\title{
Skin manifestations of tick bites in humans*
}

\author{
Vidal Haddad Jr. ${ }^{1}$ \\ Mônica Santos 3,4
}

\author{
Michel Raineri Haddad ${ }^{2}$ \\ João Luiz Costa Cardoso ${ }^{5}$
}

DOI: http:/ /dx.doi.org/10.1590/abd1806-4841.20186378

\begin{abstract}
Ticks are blood-sucking arthropods that attach to human skin through oral devices causing diverse initial cutaneous manifestations, and may also transmit serious infectious diseases. In certain situations, the Health Teams (and especially dermatologists) may face difficulties in identifying the lesions and associating them to the parasites. To assist them in clinical diagnosis, we suggest a classification of the skin manifestations in primary lesions, which occur by the attachment the tick to the host (for toxicity and the anticoagulant substances in the saliva and/or marked inflammation by the penetration and permanence of the mouthparts) and secondary lesions that are manifestations of infections caused by rickettsia, bacteria, protozoa and fungi inoculated by the ticks.
\end{abstract}

Keywords: Arthropod vectors; Arthropods; Bites and stings; Ticks; Tick-borne diseases

\section{INTRODUCTION}

Ticks are arthropod ectoparasites of the class Arachnida, that feed on the blood of their victims. There are around 850 species, of which only $10 \%$ are of importance in human Medicine. These are distributed in the Ixodidae (hard ticks), Argasidae (soft ticks) and Nuttalliellidae families. ${ }^{1-3}$

Ticks from the Ixodidae family have a body protection shield that is resistant to moderate pressures as long as the arthropod is not engorged due to ingestion of blood. "Hard" ticks will painlessly attach to their hosts and will remain until they change their phase in the life cycle, when they detach and fall to the ground (Figure 1). They are associated to infestations in humans, what can happen accidentally since they are natural hosts of wild and domesticated animals, such as horses and cattle, and pastures are risk areas for humans to acquire the parasites. ${ }^{1-3}$

Ticks from the Argasidae family do not have the protective shield and are almost always parasitic to birds, with no medical importance as well as the single species from the Nuttalliellidae family.
Larvae have six legs, while nymphs and adults have eight. All life cycle phases cause the same allergic and toxic reactions in humans, and can inoculate infectious agents such as rickettsia, bacteria, protozoa and fungi. Either larvae, nymphs or adults attach themselves to the victims through a serrated mouthpart that makes the removal of the tick difficult without breakage and permanence of fragments in the host. Larval infestation tends to be massive, with a large number of parasites and lesions, however, the initial perception of the presence of the arthropods is difficult due to the small size of the larvae and nymphs, and even young adults (Figure 2).

In Brazil, among the main genera and species that can be parasitic to man are the genera Amblyomma (parasites of wild and domesticated animals and main human parasites), Ixodes (birds), Rhipicephalus, Anocentor and Boophilus (respectively, parasites of dogs, horses and cattle, with occasional infestation in humans). The species Amblyomma cajennense (commonly known as "Cayenne tick") is the species more commonly associated to human parasitism in tropical regions (Figure 3)..$^{1-3}$

\footnotetext{
Received on 17.08.2016.

Approved by the Advisory Board and accepted for publication on 13.10.2017.

* Study conducted at Faculdade de Medicina de Botucatu - Universidade Estadual Paulista "Júlio de Mesquita Filho" (UNESP) - Botucatu (SP), Brazil. Financial support: None. Conflict of interest: None.

Department of Dermatology and Radiotherapy - Faculdade de Medicina de Botucatu - Universidade Estadual Paulista (UNESP) - Botucatu (SP), Brazil. Department of Internal Medicine - Faculdade de Medicina de São José do Rio Preto (FAMERP) - São José do Rio Preto (SP), Brazil.

Department of Dermatology - Universidade Estadual do Amazonas (UEAM) - Manaus (AM), Brazil.

Outpatient Clinic of Tropical Dermatology - Fundação Alfredo da Matta (FUAM) - Manaus (AM), Brazil.

Clínica Dermatológica Ubatuba - Ubatuba (SP), Brazil.
}

MAILING ADDRESS:

Vidal Haddad Jr.

Email: haddadjr@fmb.unesp.br

C2018 by Anais Brasileiros de Dermatologia 

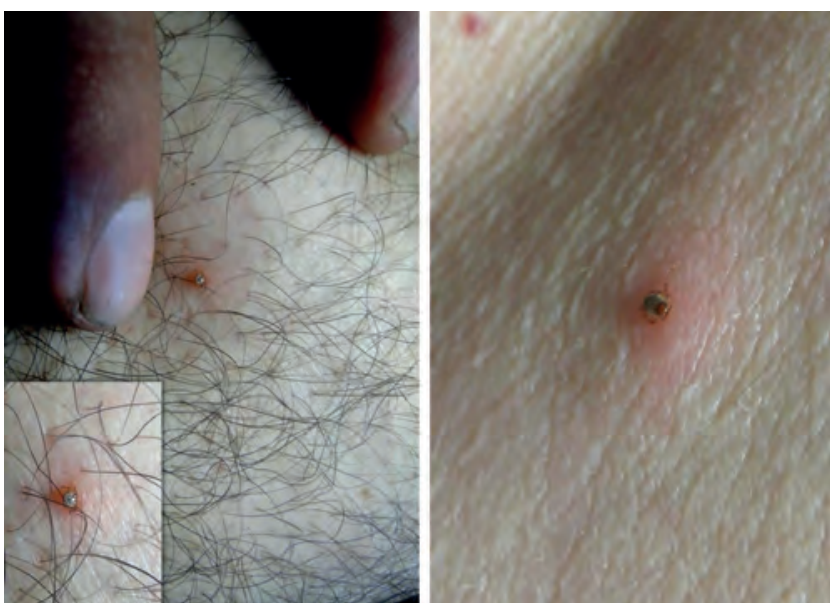

Figure 1: Adult ticks of the Amblyomma genus attached to human skin. The mouthparts of these arthropods are serrated and hard to extract. The permanence of fragments causes foreign body-type granulomas. Photos: Vidal Haddad Jr.

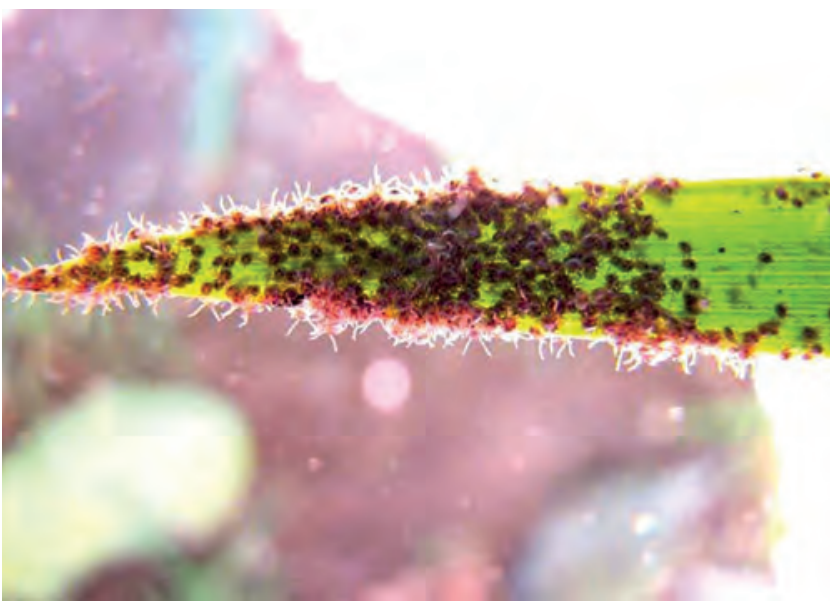

Figure 2: Hexapod larvae on a plant leaf. When an animal brushes on the leaf, the arthropods infest the victim in a large number. Photo: Tietta Pivatto

\section{CLINICAL MANIFESTATIONS}

Tick bites cause different cutaneous manifestations in humans. In some situations, health teams (and particularly dermatologists) can face difficulties to identify the lesions and associate them to the parasites. ${ }^{4}$ To aid in the clinical diagnosis, we propose the following classification (Chart 1):

1. PRIMARY LESIONS: they occur with the tick attached to the host, due to toxicity and anticoagulating substances found in the saliva and inflammation due to the penetration and permanence of the mouthparts.

IMMEDIATE REACTIONS: the acute pruritic papular dermatitis is caused by adult ticks (one or a few ticks) or by larvae (multiple parasites, the so-called micuins, in Portuguese language). When the infestation is due to larvae, these are grouped in a large number on the tips of bush leaves and attach to the victim when they brush the plants (Figure 2). The ticks spread from an initial point of contact originating the "comet tail" sign (Figure 4). ${ }^{4}$

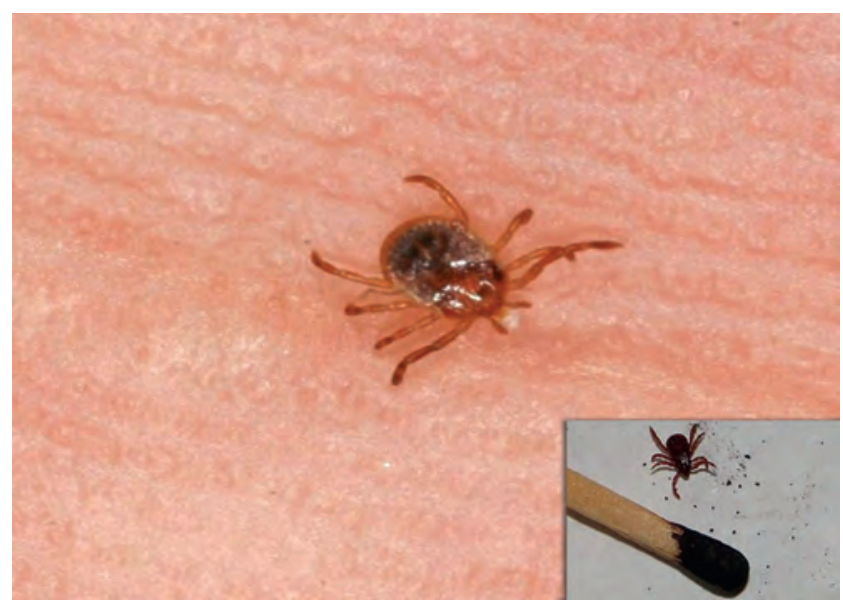

Figure 3: Ticks of the Ixodidae family (Amblyomma sp.) on human skin. Photos: Vidal Haddad Jr.

The papules caused by larvae bites are erythematous and firm, not easily breaking. Occasionally, central vesicles can be seen on the papules. Hundreds of lesions can be seen on the same victim, causing a marked pruritic clinical picture (Figure 5). The larvae fall to the ground after sucking blood from the host and evolve into nymphs, which repeat the cycle.

The manifestations caused by adult ticks are similar, but in smaller number and, sometimes, by only one specimen, when we can see the engorged tick over the lesion.

The most commonly affected sites are lower limbs (mainly ankles and legs), but the papules can manifest all over the skin due to the moving of the arthropods. Ticks have predilection for body folds and these areas should be carefully examined in massive infestations. The differential diagnosis is with other dermatozoonoses, including red fire ants, mosquitoes and fly bites (stilts and horse flies). Systemic antihistamines and topical steroids will help control the symptoms, but systemic steroids can be needed in massive infestations with a large number of bites. The lesions can become secondarily infected and warrant the use of topical or systemic antibiotics. ${ }^{4}$

LATE REACTIONS: they occur due to the attachment of the tick through the serrated mouthpart. Breakage of the mouthpart upon extraction leads to the retention of fragments and in the majority of cases, there is the formation of an erythematous edematous nodule where the insect was removed from. This occurs because of the permanence of fragments of the mouthparts in the skin, causing chronic foreign- body-type reactions that can last for months. The nodules are resistant to topical medications and local steroid injections are a good option to solve the problem. ${ }^{4}$

2. SECONDARY LESIONS: they are manifestations caused by rickettsia, bacterial, protozoan and fungal infections inoculated by the ticks.

LYME BORRELIOSIS: Lyme borreliosis (LB), also known as Lyme disease (LD) is an infectious, non-contagious disease caused by spirochetes of the Borrelia burgdorferi sensu lato complex and transmitted by tick bites. ${ }^{5,6}$ In most cases, it is associated to wild animal ticks, such as deer in Europe and United States, but it can also be 


\begin{tabular}{|c|c|c|}
\hline & Cause & Skin manifestations \\
\hline \multicolumn{3}{|l|}{ Primary lesions } \\
\hline Immediate reactions & Toxins and irritants in saliva & Firm papules, intense pruritus. The tick can be attached. \\
\hline Late reactions & Fragments of the mouthpart & Chronic edematous nodule, similar to a foreign body granuloma. \\
\hline \multicolumn{3}{|l|}{ Secondary lesions } \\
\hline Lyme Borreliosis & Borrelia spp. complex (spirochetes) & $\begin{array}{l}\text { Erythema migrans (centrifugally progressing plaque, "bull's eye"), } \\
\text { lymphocytoma cutis, sclerodermiform states. }\end{array}$ \\
\hline $\begin{array}{l}\text { Rocky Mountain } \\
\text { Spotted Fever }\end{array}$ & Rickettsia rickettsii & $\begin{array}{l}\text { Hemorrhagic rash with petechiae and hemorrhagic suffusion that can } \\
\text { become necrotic. }\end{array}$ \\
\hline Tick paralysis & Neurotoxins in saliva & $\begin{array}{l}\text { Ascending progressive paralysis that can lead to death. Ticks attached } \\
\text { to the skin. }\end{array}$ \\
\hline Ehrlichiosis & Ehrlichia canis (bacterium) & Erythematous or erythematous-purple non-specific rash. \\
\hline Recurrent fever & Borrelia recurrentis (spirochete) & Non-specific erythematous rash. \\
\hline Tularemia & $\begin{array}{l}\text { Francisella tularensis } \\
\text { (Gram negative coccobacillus) }\end{array}$ & Deep ulcer on the site of the bite and swollen regional lymph nodes. \\
\hline Babesiosis & Babesia canis (protozoan) & No cutaneous manifestations. \\
\hline
\end{tabular}
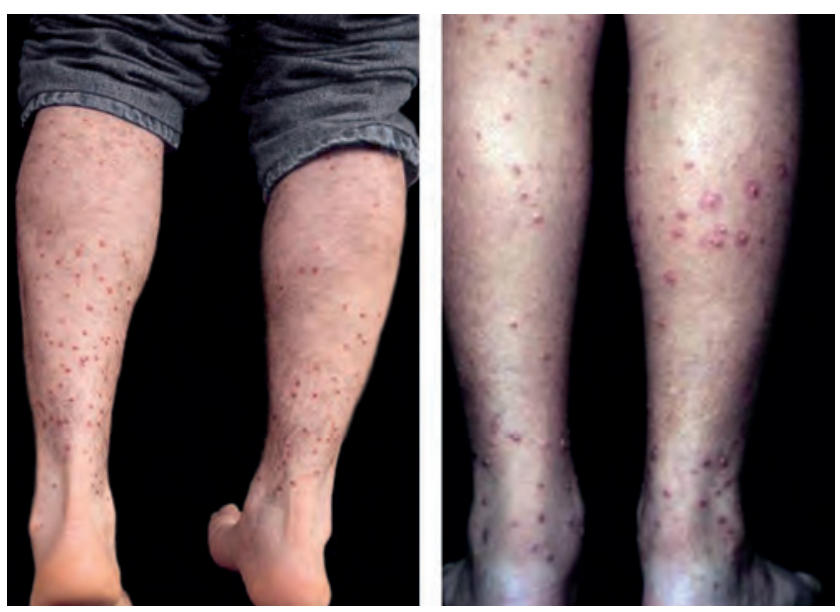

Figure 4: Dissemination of larvae from contact with clusters on plants lead to the characteristic "comet tail" sign, which is the attachment of multiple arthropods on the same site with subsequent movement, widening the bite area. Photos: João Luiz Costa Cardoso

transmitted by domesticated animal ticks such as cattle and horses. The main vectors are ticks of the Ixodes genus, but other genera such as Amblyomma (especially A. cajennense), Dermacentor and Rhipicephalus were already associated to the transmission. The initial cutaneous lesion, known as erythema migrans (EM), is characterized by the appearance of erythematous macules or papules that increase in size, forming isolated or multiple plaques with interrupted borders and lighter, purple and/or scaling center, that expands centrifugally and concentrically ("bull's eye"), and can reach large diameters (Figure 6). Even though EM can appear on any area of the skin, it predominates on the lower and upper limbs and face. It is usually asymptomatic, but pruritus or burning sensation can be reported.?

Days or weeks after the onset of cutaneous manifestations, new EM lesions can appear due to the hematogenous or lymphatic spread of the spirochetes. These lesions can appear with the prima-

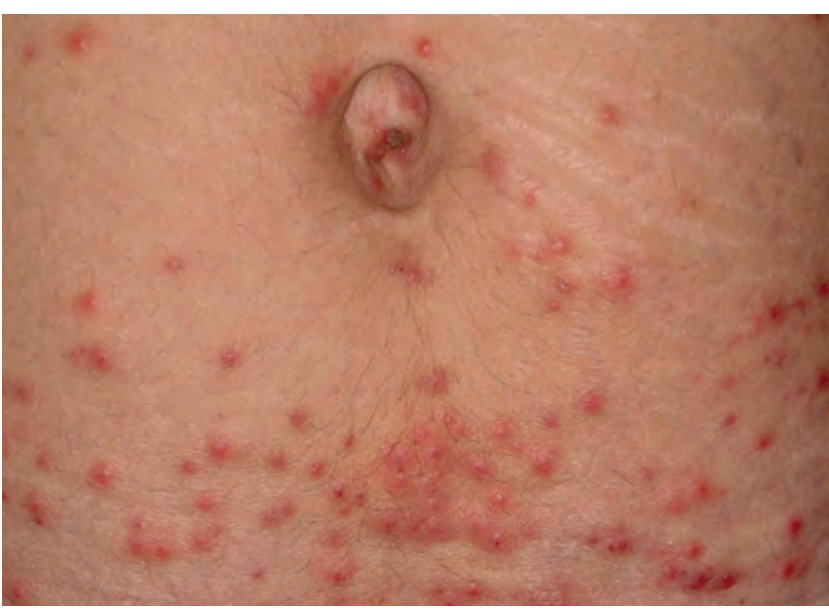

Figure 5: Massive infestation of hexapod larvae, with firm papules. In this phase, the arthropods are small and difficult to visualize. Photo: Eliete Correa Soares

ry lesion or after its disappearance. Initial LB lesions can disappear even without treatment and late manifestations can appear months or years after the initial infection. Among the main changes are joint, cardiac, neurologic, ophthalmologic and chronic cutaneous involvement, represented by acrodermatitis chronica atrophicans (ACA). Rarely, these late manifestations can occur concomitantly to EM lesions. ACA, also known as Pick-Herxheimer disease, is considered typical for borreliosis and is more common in Europe. It starts as an erythematous plaque that evolves to atrophic plaques with visible and prominent blood vessels occurring mainly on body extremities, but also trunk and face (Figure 7). Borreliosis is also associated to other dermatological conditions, such as plaque scleroderma, lichen sclerosus et atrophicus, anetodermas, atrophoderma of Pasini-Pierini (APP) and granuloma annulare. ${ }^{8}$

Lyme borreliosis treatment for the initial manifestations is 


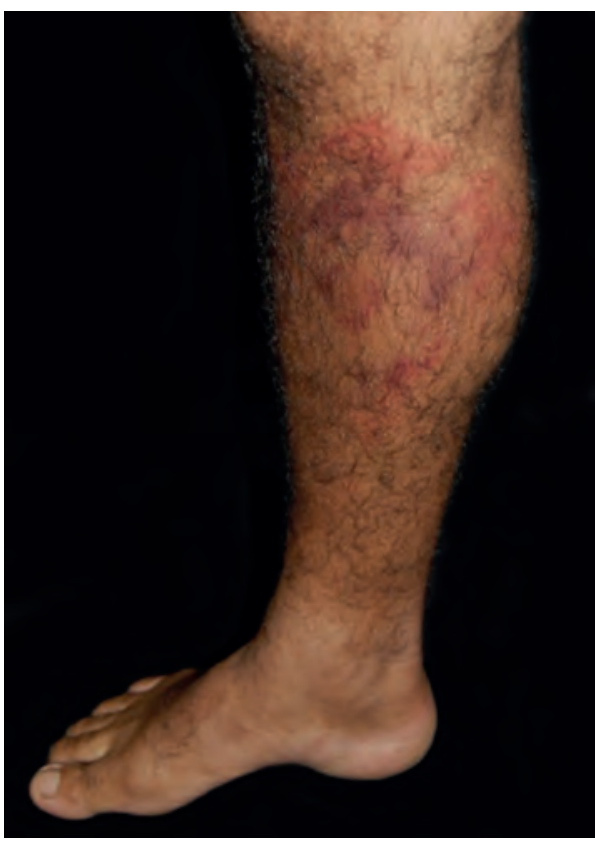

Figure 6: Bull's eye sign in erythema migrans is indication of the initial manifestation of Lyme borreliosis and is caused by the dissemination of the spirochete in a concentric fashion. Photo: Mônica Soares

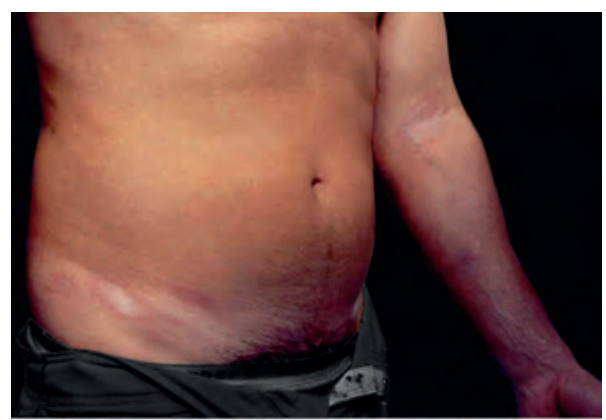

Figure 7: Infections caused by Borrelia sp. Can be associated to chronic sclerodermiform states. Among those, it is possible to see plaque scleroderma (such as in this patient with positive serology for Borrelia and spirochetes on histopathology). Photo: João Luiz Costa Cardoso with doxycycline $100 \mathrm{mg}$ bd for 14 days. When there are cardiac or neurologic manifestations, ceftriaxone $2 \mathrm{~g}$ / day IV, for 21 to 28 days should be given. In the presence of joint involvement, treatment is made with doxycycline $100 \mathrm{mg}$, every $12 / 12$ hour orally, for a minimum of 28 days. $^{9}$

ROCKY MOUNTAIN SPOTTED FEVER (RMSF): caused by Rickettsia rickettsii. The manifestations have a sudden onset, with a flu-like state that lingers for 2 to 3 weeks. On the $3^{\text {rd }}$ or $4^{\text {th }}$ day, a maculopapular rash appears, erythematous in color with pale tones. It begins on the wrists and ankles, and can spread to the lower and upper limbs and trunk. Around the $6^{\text {th }}$ day, the lesions can become purpuric (with the formation of petechiae), which is a sign of severe disease, indicating generalized vasculitis due to the multiplication of the agent in endothelial cell of small vessels (Figure 8)..$^{10-12}$

RMSF can progress with no symptoms or mild symptoms but, on the other end, some cases progress with extensive cutaneous necrosis in areas of hemorrhagic suffusions. Drowsiness, psychomotor agitation and meningeal signs are common. The face becomes congested and edematous, with edema around the eyelids and conjunctival erythema. Cough and arterial hypotension can be seen. RMSF is a serious disease with a mortality of around $20 \%$ in non-treated cases. Early treatment with antibiotics (doxycycline in mild to moderate cases and chloramphenicol IV in severe cases) reduces mortality to minimum rates.

TICK PARALYSIS: tick paralysis is an acute, little known disease, caused by toxins in the saliva of ticks of many genera. They block neuromuscular transmission, leading to an ascending flaccid paralysis with quick onset (hours to days) that can culminate with respiratory arrest and death. It is a well-described condition in domesticated animals, but can also manifest in humans; it was described in Canada, United States, Australia, Europe, Africa, Argentina and Brazil. ${ }^{13-15}$ The tick must be attached to confirm the diagnosis and the removal of the arthropod makes the symptoms regress
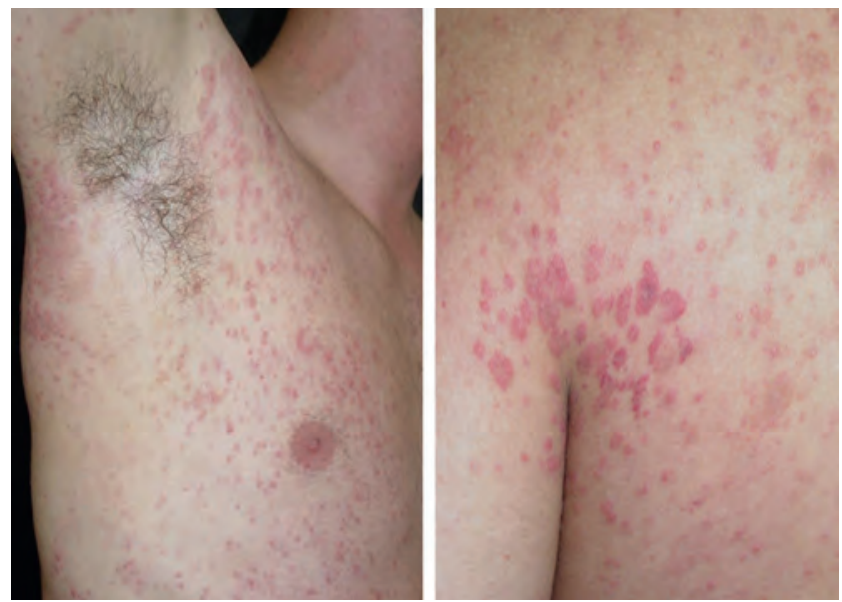

FIGURE 8: The early papular rash on the wrists and ankles can spread and become purpuric (petechiae), a sign of increasing severity in rocky mountain spotted fever. Photos: Department of Dermatology FMB UNESP

dramatically, with no sequelae. Treatment is symptomatic, and is especially indicated when there is respiratory failure. ${ }^{13-15}$

EHRLICHIOSIS (mainly Ehrlichia canis): disease increasing in dogs because of tick bites (Rhipicephalus sanguineus). It can affect humans. Infection causes general symptoms, high fever, nausea, vomiting and erythematous or erythematous-purplish non-specific rash. Treatment is with doxycycline. ${ }^{16-18}$

TULAREMIA (Francisella tularensis): the infection caused by this bacteria manifest with high fever, nausea and vomiting, headaches, deep ulcer on the site of the bite and swollen regional lymph nodes. Streptomycin is the antibiotic of choice for the treatment of tularemia and gentamycin is a less effective option. ${ }^{16-18}$ 
RECURRENT FEVER: caused by Borrelia recurrentis (spirochete), it manifests with high fever, muscle and abdominal pain and non-specific rash in $50 \%$ of cases. Tetracycline, doxycycline or erythromycin orally will cure the infection. . $^{16,17}$

COLORADO TICK FEVER (Reoviridae family, genus Coltivirus): no dermatologic signs. Treatment is symptomatic. ${ }^{16}$

BABESIOSIS (mainly Babesia microti, a protozoan): no skin manifestations. Babesiosis is treated with the association of an antibiotic (clindamycin or azithromycin) and an antiparasitic such as quinine or atovaquone. ${ }^{16,17}$

Ticks should be removed as early as possible, for their permanence in the site of attachment has a direct relationship with the resulting inflammation and with the transmission of infectious agents or propagation of toxins. To remove them correctly, it is important to use curved fine tweezers. Wash the hands thoroughly with an antibacterial soap before and after the procedure. Nymphs and adults are found in areas of moist and warm thin skin such as axillae, inguinal regions, ankles and scalp.

For the removal, the tweezers should not grasp the tick's body or head, but below its head, close to the skin. Compression of the body or head can release a large quantity of contaminated saliva into the host, disseminating infectious agents. The tick should be pulled upwards in a straight line, with a slow and steady movement, without twisting or compressing. After removal, check if any part of the tick was left behind in the surface of the skin. It is necessary to clean the area with antiseptic soap and water and use an antibacterial ointment. To repel ticks, picaridin or DEET on the skin and permethrin on the external surface of clothes, shoes and tents are recommended.

\section{CONCLUSIONS}

The manifestations caused by tick bites in humans are variable, with acute, non-specific lesions and late lesions that are, in the majority of cases, linked to infections. These manifestations have their own features and should be recognized by health teams because they can suggest the diagnosis of serious conditions. Acute lesions that appear shortly after the bites are firm, extremely pruritic papules, while the chronic ones are erythematous and/or atrophic plaques on the sites of the bites, that provide clues to the diagnosis of bacterial and viral diseases. $]$

\section{REFERENCES}

1. Dantas-Torres F, Onofrio VC, Barros-Battesti DM. The ticks (Acari: Ixodida: Argasidae, Ixodidae) of Brazil. Syst Appl Acarol. 2009;14:30-46.

2. Vieira AML, Souza CE, Labruna MB, Mayo RC, Souza SSL, Camargo-Neves VLF. Manual de Vigilância Acarológica. Estado de São Paulo. Secretaria de Estado da Saúde - Superintendência de Controle de Endemias (SUCEN São Paulo). São Paulo: Editora do Estado; 2002.

3. Serra Freire NM, Sena LM, Borsoi AB. Parasitismo humano por carrapatos na Mata Atlântica, Rio de Janeiro, Brasil. Entomo Brasilis. 2011;4:67-72.

4. Haddad Jr V. Identification of acute diseases caused by animals and plants in wild environments: contribution to dermatologic practice. An Bras Dermatol. 2009;84:343-8.

5. Steere AC, Malawista SE, Snydman DR, Shope RE, Andiman WA, Ross MR, et al. Lyme arthritis: an epidemic of oligoarticular arthritis in children and adults in three Connecticut communities. Arthritis Rheum. 1977;20:7-17.

6. Burgdorfer W, Barbour AG, Hayes SF, Benach JL, Grunwaldt E, Davis JP. Lyme disease, a thick-borne spirochetosis? Science. 1982;216:1317-9.

7. Talhari S, de Souza Santos MN, Talhari C, de Lima Ferreira LC, Silva RM Jr, Zelger $B$, et al. Borrelia burgdorferi "sensu lato" in Brazil: Occurrence confirmed by immunohistochemistry and focus floating microscopy. Acta Trop. 2010;115:200-4.

8. Santos M, Ribeiro-Rodrigues R, Talhari C, Ferreira LC, Zelger B, Talhari S. Presence of Borrelia burgdorferi "Sensu Lato" in patients with morphea from the Amazonic region in Brazil. Int J Dermatol. 2011;50:1373-8.
9. Santos M, Haddad Jr V, Ribeiro-Rodrigues R, Talhari S. Lyme borreliosis. An Bras Dermatol. 2010; 85:930-8.

10. Meira DA, Campos EP. Febre maculosa: apresentação de um caso clínico. Rev Soc Bras Med Trop. 1982;15:122-4.

11. Pinter A, França AC, Souza CE, Sabbo C, Nascimento EMM, Santos FCP, et al Febre maculosa brasileira. Bol Epidemiol Paulista. 2011;8:3- 31.

12. Angerami RN, Câmara M, Pacola MR, Rezende RC, Duarte RM, Nascimento EM et al. Features of Brazilian spotted fever in two different endemic areas in Brazil. Ticks Tick Borne Dis. 2012;3:346-8

13. Edlow JA, McGillicuddy DC. Tick paralysis. Infect Dis Clin North Am 2008;22:397-413.

14. Serra Freire NM. Tick paralysis in Brazil. Trop Anim Health Prod. 1983;15:124-26.

15. Almeida RAMB, Ferreira MA, Barraviera B, Haddad Jr V. The first reported case of human tick paralysis in Brazil: a new induction pattern by immature stages. J Venom Anim Toxins incl Trop Dis. 2012;18:459-61.

16. Spach DH, Liles WC, Campbell GL, Quick RE, Anderson DE Jr, Fritsche TR. TickBorne Diseases in the United States. N Engl J Med. 1993;329:936-47.

17. Kernif T, Leulmi H, Raoult D, Parola P. 2016. Emerging Tick-borne bacterial pathogens. Microbiol Spectrum. 2016;4:El10-0012.

18. McGinley-Smith DE, Tsao SS. Dermatoses from ticks. J Am Acad Dermatol. 2003;49:363-92.

How to cite this article: Haddad Jr V, Haddad MR, Santos M, Cardoso JLC. Skin manifestations of tick bites in humans. An Bras Dermatol. 2018;93(2):251-5. 